\title{
A genome-wide RNA interference screen identifies new regulators of androgen receptor function in prostate cancer cells
}

\author{
Keren Imberg-Kazdan, ${ }^{1}$ Susan Ha, ${ }^{1,2}$ Alex Greenfield, ${ }^{3}$ Christopher S. Poultney, ${ }^{3,6}$ \\ Richard Bonneau, ${ }^{3}$ Susan K. Logan, ${ }^{1,2,4}$ and Michael J. Garabedian ${ }^{2,3,4,5,7}$ \\ ${ }^{1}$ Department of Biochemistry and Department of Molecular Pharmacology, New York University School of Medicine, New York, \\ New York 10016, USA; ${ }^{2}$ Department of Urology, New York University School of Medicine, New York, New York 10016, USA; ${ }^{3}$ Center \\ for Genomics and Systems Biology, New York University, New York, New York 10003, USA; ${ }^{4}$ NYU Cancer Institute, New York University \\ School of Medicine, New York, New York 10016, USA; ${ }^{5}$ Department of Microbiology, New York University School of Medicine,
} New York, New York 10016, USA

\begin{abstract}
The androgen receptor (AR) is a mediator of both androgen-dependent and castration-resistant prostate cancers. Identification of cellular factors affecting AR transcriptional activity could in principle yield new targets that reduce AR activity and combat prostate cancer, yet a comprehensive analysis of the genes required for AR-dependent transcriptional activity has not been determined. Using an unbiased genetic approach that takes advantage of the evolutionary conservation of AR signaling, we have conducted a genome-wide RNAi screen in Drosophila cells for genes required for AR transcriptional activity and applied the results to human prostate cancer cells. We identified 45 AR-regulators, which include known pathway components and genes with functions not previously linked to AR regulation, such as HIPK2 (a protein kinase) and MED19 (a subunit of the Mediator complex). Depletion of HIPK2 and MED19 in human prostate cancer cells decreased AR target gene expression and, importantly, reduced the proliferation of androgen-dependent and castration-resistant prostate cancer cells. We also systematically analyzed additional Mediator subunits and uncovered a small subset of Mediator subunits that interpret AR signaling and affect AR-dependent transcription and prostate cancer cell proliferation. Importantly, targeting of HIPK2 by an FDA-approved kinase inhibitor phenocopied the effect of depletion by RNAi and reduced the growth of AR-positive, but not AR-negative, treatment-resistant prostate cancer cells. Thus, our screen has yielded new AR regulators including drugable targets that reduce the proliferation of castration-resistant prostate cancer cells.
\end{abstract}

[Supplemental material is available for this article.]

The androgen receptor (AR) is a ligand-regulated transcription factor that plays a key role in the development and function of the prostate gland (Dehm and Tindall 2007) and directs many other aspects of human physiology including anabolic actions in both bone and skeletal muscle. Upon binding to androgen, AR translocates to the nucleus and binds DNA regulatory sequences of target genes in association with coactivators and corepressors to direct gene transcription (Heemers and Tindall 2007).

AR signaling is complex. While normal prostate epithelial cells grow in response to androgen stimulation by adjacent stromal tissue (Cunha and Donjacour 1987), prostate cancer cells appear to proliferate in direct response to androgens (Gao et al. 2001). The complexity of AR action is likely achieved through cellular factors that modulate AR function and direct prostate cell context-specific effects (Chang and McDonnell 2005).

Given such complexity, it is not surprising that AR signaling drives both early androgen-dependent as well as late castration resistant prostate cancer (CRPC) that does not respond to andro-

\footnotetext{
${ }^{6}$ Present address: Seaver Autism Center for Research and Treatment, Department of Psychiatry, Mount Sinai Medical Center, New York, NY 10029, USA.

${ }^{7}$ Corresponding author

E-mail michael.garabedian@nyumc.org

Article published online before print. Article, supplemental material, and publication date are at http://www.genome.org/cgi/doi/10.1101/gr.144774.112.
}

gen deprivation therapy (Chen et al. 2004). In fact, improved therapy of CRPC could result from targeting cellular factors that control AR activity (Nabhan et al. 2011). Although the role of the AR in prostate health and disease has been illuminated by highthroughput genomic (Wang et al. 2009; Sharma et al. 2013), metabolomic (Sreekumar et al. 2009), and chemical-biology approaches (Norris et al. 2009), systematic profiling of the genes that functionally regulate AR action has not been conducted.

To identify functional regulators of the AR, we performed a genome-wide RNAi screen to determine putative new AR cofactors, pathways, and targets for prostate cancer therapy. This approach has uncovered new cellular factors that affect AR-dependent transcriptional and proliferative responses in prostate cancer cells.

\section{Results}

\section{Genome-wide RNAi screen for new AR regulators}

To identify new regulators of AR activity, we conducted a genomewide RNAi screen using AR transcriptional activation as measured by reporter gene activity in Drosophila S2 cells upon stimulation with $10 \mathrm{nM}$ of the synthetic androgen R1881 (Supplemental Fig. 1A; Yoshinaga and Yamamoto 1991; Echeverri and Perrimon 2006; DasGupta et al. 2007). This concentration enabled identification of both positive and negative modulators. The activity of the ligand-induced AR-dependent transcription pathway is quantified 
by normalization of the ratio of the absolute activity of Firefly luciferase to that of Renilla luciferase (Supplemental Fig. 1B,C).

We screened two independent Drosophila RNAi libraries for AR modulators (Supplemental Fig. 1D): (1) a whole-genome library consisting of double-stranded RNAs (dsRNAs) targeting 13,900 genes; and (2) an independent kinase/phosphatase library that targets 468 genes with greater coverage than the whole-genome library. We analyzed the data using multiple statistical protocols and selected candidates based on their deviation from the plate average (Supplemental Methods).

Because enhanced AR activity fuels advanced prostate cancer, the goal of the screen was to identify positive regulators that when reduced, decreased AR activity, although negative regulators of AR activity were also identified (Supplemental Fig. 1E). We selected $\sim 200$ genes that reduced AR activity for confirmation in the secondary screen (Supplemental Fig. 1F). The secondary screen not only validated the candidate genes for effects on AR transcriptional activation, but also tested specificity by comparing the effect of the depletion on the activity of the glucocorticoid receptor (GR). GR was chosen because while AR and GR can bind to the same DNA sequences, they exert different biological effects.

We validated 45 genes that when depleted, reduced ARdependent transcriptional activation. Of these, 21 were AR-specific activators: Depletion affected AR transcriptional activation to a greater extent than GR (Table 1; Supplemental Table 1A). The remaining 24 were not specific for AR: Depletion affected AR and GR hormone-dependent transcriptional activation to similar extents (Supplemental Table 1B). Genes that selectively decreased AR transcriptional activity upon depletion were examined in human prostate cancer cells (Table 1).

Importantly, several of the known regulators of AR were identified, thus validating the experimental approach (Table 1),

Table 1. Factors that inhibit AR-dependent transcription when reduced by RNAi

\begin{tabular}{|c|c|}
\hline \multicolumn{2}{|l|}{ Kinases } \\
\hline HIPK2 ${ }^{a}$ & Serine/threonine nuclear kinase, interacts with transcription factors \\
\hline GSK3B ${ }^{b}$ & Serine-threonine kinase; Wnt signaling pathway \\
\hline $\mathrm{DGKI}^{\mathrm{a}}$ & Lipid kinase; phosphorylates DAG, producing phosphatidic acid \\
\hline \multicolumn{2}{|l|}{ Phosphatases } \\
\hline CDC $25 A^{\mathrm{b}}$ & Dephosphorylates and activates the cyclin-dependent kinase \\
\hline $\mathrm{CDC} 25 \mathrm{~B}^{\mathrm{b}}$ & Dephosphorylates and activates the cyclin-dependent kinase CDC2 \\
\hline \multicolumn{2}{|c|}{ Nuclear functions } \\
\hline PHACTR3 $^{\mathrm{a}}$ & Associated with the nuclear scaffold \\
\hline MED19a & Component of the Mediator coactivator complex \\
\hline $\mathrm{MXD1}^{\mathrm{a}}$ & Protein competes with MYC for binding to MAX \\
\hline NUP153 $3^{a}$ & Subunit of the nuclear pore complex \\
\hline DDX39B ${ }^{a}$ & DEAD-box family of RNA-dependent ATPases \\
\hline $\mathrm{HLF}^{\mathrm{a}}$ & Human hepatic leukemia factor; a bZIP transcription factor \\
\hline $\mathrm{FOXO}^{\mathrm{b}}$ & Forkhead family transcription factor \\
\hline $\mathrm{CREB}^{\mathrm{a}}$ & Transcription factor \\
\hline CREBBP ${ }^{\mathrm{b}}$ & CREB binding protein-transcriptional coactivator \\
\hline $\mathrm{EP} 300^{\mathrm{b}}$ & Transcriptional coactivator: HAT-regulates transcription via chromatin \\
\hline HHEX $^{\mathrm{a}}$ & Homeobox transcription factor; enhances canonical WNT signaling \\
\hline CSTF2T ${ }^{\mathrm{a}}$ & Binds pre-mRNAs \\
\hline HNRNPA $1^{\text {b }}$ & Influences pre-mRNA processing \\
\hline \multicolumn{2}{|l|}{ Signaling } \\
\hline CELSR1 ${ }^{a}$ & Nonclassic cadherin \\
\hline GPR179a & Orphan GPCR \\
\hline $\mathrm{FHL} 2^{\mathrm{b}}$ & Links various signaling pathways with transcriptional regulation \\
\hline MRPL40 & Nuclear-encoded mitochondrial ribosomal \\
\hline $\mathrm{RPH} 3 \mathrm{~A}^{\mathrm{b}}$ & Protein transport \\
\hline
\end{tabular}

aPotential new AR regulators.

${ }^{b}$ Factors previously shown to affect AR activity. including GSK3B (Wang et al. 2004), CDC25A (Chiu et al. 2009), CDC25B (Ngan et al. 2003), FOXO3 (Lupien et al. 2008), EP300 (Fu et al. 2000), CREBBP (Comuzzi et al. 2003), HNRNPA1 (Yang et al. 2007), and FHL2 (Muller et al. 2000). New AR regulators include the serine/threonine kinase HIPK2 (Rinaldo et al. 2007); the lipid kinase DGKI (Raben and Tu-Sekine 2008); nuclear factors PHACTR3 (also known as scapinin), which is an actin and PP1 phosphatase-binding protein associated with the nuclear scaffold (Sagara et al. 2003, 2009); MED19, a component of the Mediator complex (Baidoobonso et al. 2007); and MXD1, which competes with MYC for binding to MAX (Wahlstrom and Henriksson 2007). Other factors identified were NUP153, subunit of the nuclear pore complex (Ball and Ullman 2005); DDX39B (also known as BAT1), an RNA helicase involved in mRNA splicing and transport (Peelman et al. 1995); HLF (Hunger et al. 1992) and CREB1 (Siu and Jin 2007), both bZIP transcription factors; HHEX, a homeobox transcription factor (Bedford et al. 1993); and CSTF2T, a pre-mRNA binding protein (Takagaki and Manley 1997). Signaling molecules not previously linked to AR activity were also identified and include CELSR1, a nonclassical cadherin involved in cell-cell communication (Hadjantonakis et al. 1997); GPR179, an orphan G-coupled protein receptor (Bjarnadottir et al. 2005); $R P H 3 A$, involved in protein transport and vesicle exocytosis (Inagaki et al. 1994); and MRPL40, nuclear-encoded mitochondrial ribosomal protein (Kenmochi et al. 2001).

\section{Evaluation of AR-specific regulators in human prostate cancer cells}

We examined the mRNA expression of the AR-specific regulators in human prostate cells by qPCR and in human prostate tissue through the Human Protein Atlas (Persson et al. 2006). We were able to detect mRNA expression of virtually all of the factors in human prostate cancer cell lines, LNCaP and LNCaP-abl cells (Supplemental Fig. 2). LNCaP cells are androgen dependent for growth, while LNCaP-abl cells are derived from LNCaP cells isolated for their ability to grow in the absence of androgen, and as such, represent a model for castration-resistant prostate cancer (Culig et al. 1999). The regulators also appeared to be expressed at the protein level in human prostate epithelial cells (Supplemental Fig. 3; Supplemental Table 2), with the exception of DGKI, which appears to be expressed in prostate stromal, but not epithelial cells, and RPH3A, which does not appear to be expressed in prostate tissue.

We also examined if AR activators identified in the screen might be up-regulated in prostate cancer. We found that HIPK2 and MED19 mRNA were up-regulated in, respectively, $32 \%$ and $23 \%$ of the 85 cases examined (Supplemental Fig. 4; Taylor et al. 2010). Other factors from the screen were also up-regulated in cancer albeit to lesser extents (e.g., GSK3B, FOXO3, GRP179). In contrast, CELSR1, FHL2, and $H L F$ mRNAs were largely down-regulated in prostate cancer (Supplemental Fig. 4),

\section{Genome Research} www.genome.org 
suggesting that these factors play a different role in AR function from those up-regulated, for example, by promoting AR-dependent differentiation rather than proliferation. Importantly, dysregulation of MED19 was associated with lower rates of survival in men with prostate cancer (Supplemental Fig. 5A). Although alterations in HIPK2 mRNA were not linked to changes in long-term survival (Supplemental Fig. 5B), it is likely that activity, rather than expression, is important in kinase-driven carcinogenesis.

We next tested whether the factors would affect AR transcriptional activity in human prostate cancer cells. The LNCaP cell line stably expressing an AR-responsive probasin-luciferase reporter gene (Link et al. 2005) was transfected with siRNAs against the human homologs of the 21 factors. A majority of the AR regulators showed reduced AR transcriptional activation when depleted by siRNA (Fig. 1A). Depletion of CDC25A, CDC25B, GSK3B, HIPK2, PHACTR3, EP300, MED19, and DDX39B reduced AR transcriptional activity between $40 \%$ and $60 \%$ compared with the control. In contrast, depletion of NUP135, MXD1, and FHL2 had virtually no effect on activation of the AR reporter gene. Gene knockdown was confirmed by examining the mRNA level, and in most cases, the gene depletion resulted in a $>60 \%$ reduction in mRNA expression (Fig. 1B). Consistent with the observations in Drosophila cells, a majority of the AR regulators were capable of affecting AR-dependent transcriptional activation of the reporter gene in human prostate cancer cells.

Next, we tested whether depletion of these gene products would reduce AR-dependent proliferation of prostate cancer cells. For this assay, we used LNCaP-abl cells, since they represent a model for aggressive CRPC and therefore are the relevant cell type to interrogate potential new targets. LNCaP-abl cells were trans- fected with siRNAs against each factor, and cell proliferation was measured after $7 \mathrm{~d}$ (Fig. 1C). Many of the genes affected proliferation when depleted, which largely mirrored their effects on AR-dependent transcription. MED19, CDC25A, MRPL40, CREB1, CSTF2T, CDC25B, NUP153, FOXO3, and HIPK2 all reduced cell proliferation. Depletion of GRP179, HHEX, CELSR1, PHACTR3, $D D X 39 B$, and $G S K 3 B$ also affected proliferation, albeit to a lesser extent. FHL2 and MDX1, despite efficient knockdown (Fig. 1D), had little impact on proliferation. AR expression was largely unaffected by knockdown of the candidate genes (Supplemental Fig. 6). The fact that reduction of some factors has a greater effect on cell proliferation than depletion of AR suggests that targets in addition to AR might be affected.

Together, identification of factors that exert both effects on AR-dependent transcription and proliferation reveals a list of potential new AR regulators in prostate cancer cells. Two genes not previously linked to AR activity that reduced AR-dependent transcription and CRPC proliferation were the protein kinase HIPK2 and the Mediator subunit MED19. We selected these genes for further analysis because as a kinase, HIPK2 has the potential to be targeted by small-molecule inhibitors. MED19 was selected because it had the most potent effect on LNCaP-abl cellular proliferation. We also found that both HIPK2 and MED19 proteins associate with AR as assessed by coimmunoprecipitation (Supplemental Fig. 7). In addition, HIPK2 and MED19 mRNA were up-regulated in a subset of prostate cancers, and dysregulation of MED19 mRNA was associated with poor prognosis, lending relevance for the potential of these factors to fuel prostate cancer.
A

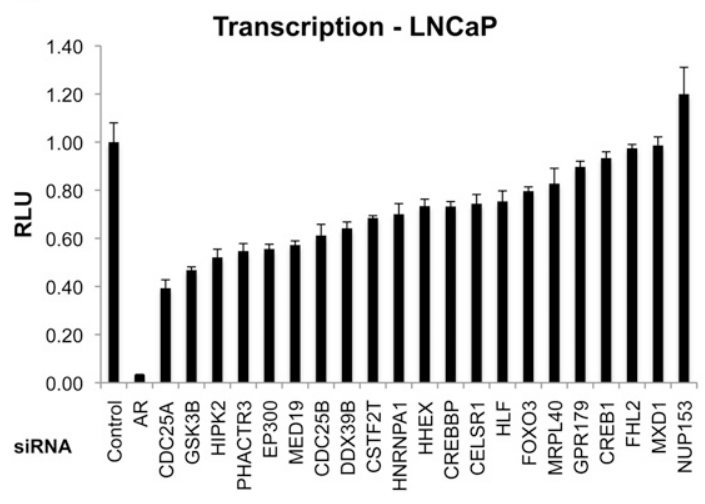

B

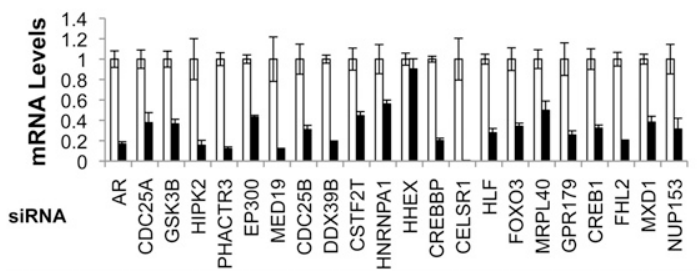

C

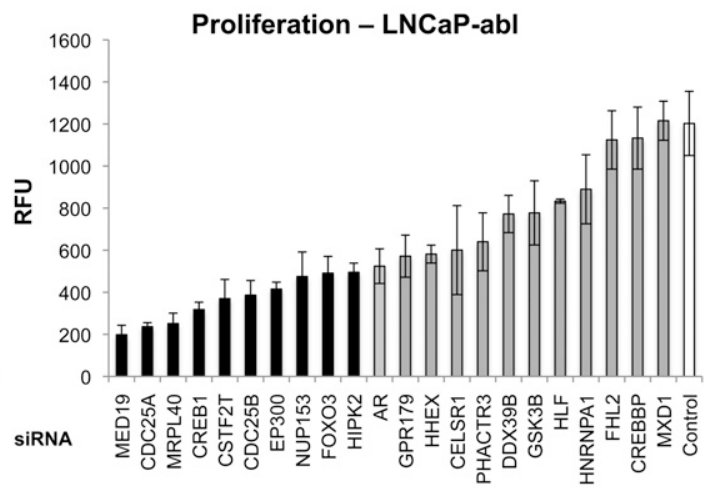

D

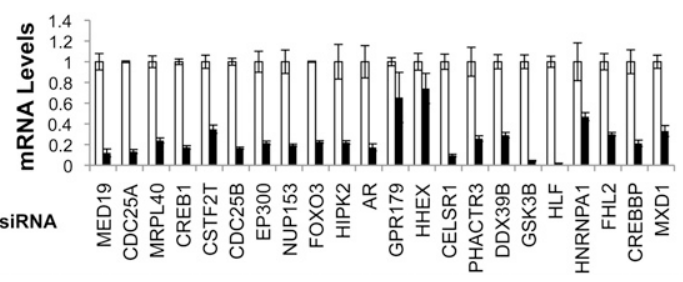

Figure 1. Effect of the AR regulators on AR-dependent transcriptional activity and cell proliferation in human prostate cancer cells. $(A) \mathrm{LNCaP}$ cells stably expressing an AR-responsive probasin-luciferase reporter gene were transfected with siRNAs against the indicated factors or a scrambled, nonsilencing siRNA (control), and after $48 \mathrm{~h}$, were treated with $10 \mathrm{nM} \mathrm{R} 1881$ for $24 \mathrm{~h}$. Luciferase activity was measured, normalized to protein, and presented as relative luminescence units (RLUs). (B) The efficiency of knockdown of each factor was determined at the mRNA level relative to RPL19 and shown as relative mRNA expression. (White bars) Nonsilencing siRNA; (black bars) the indicated siRNAs. (C) LNCaP-abl cells were transfected with siRNAs against the indicated factor or a scrambled siRNA for the control cells, and cell proliferation was measured after $7 \mathrm{~d}$. Data are represented as relative fluorescence units (RFUs). $(D)$ The extent of knockdown was determined and represented as in $B$, and relative mRNA expression is shown. The experiment was performed in triplicate with error bars representing the standard deviation. 
MED19 and HIPK2 depletion reduce AR target gene expression in prostate cancer cells

We evaluated the effect of HIPK2 and MED19 on endogenous AR target gene expression in both LNCaP and LNCaP-abl cell lines. Reduction of MED19 by siRNA in LNCaP cells reduced the androgen-dependent expression of PSA, NKX3.1, and FKBP5 (Fig. 2A). Likewise, depletion of MED19 in LNCaP-abl cells reduced the expression of the AR-target genes, important for growth in castration levels of androgen, UBE2C, CDC2O, CCNA, and CDK1 (Fig. 2B). MED19 depletion in LNCaP-abl cells also reduced the mRNA expression of $F K B P 5$, and to a lesser extent NKX3.1, but not PSA, suggesting cell type- and promoter-specific regulation of AR by MED19.

Because MED19 is a component of the Mediator complex, its reduction may disrupt the integrity of the entire Mediator complex, thereby altering AR-dependent gene expression. We used VP16 activity, which is known to be dependent on MED17 and MED25 (Ito et al. 1999), and GR activity, which depends on MED14 and MED1 (Hittelman et al. 1999; Chen et al. 2006), as independent indicators of the integrity of the Mediator complex. In contrast to AR, the transcriptional activity of VP16 and GR was not compromised when MED19 was reduced (Fig. 2C-F). Therefore, the loss of MED19 does not substantially alter the functional integrity of the Mediator complex and suggests that AR uses this specific Mediator component to control gene expression.
Given the impact that MED19 depletion has on AR-mediated transcriptional activity and cell proliferation, we also examined whether other Mediator subunits affect AR-dependent transcription and cellular proliferation when depleted. Reduction by siRNA of MED6, MED17, MED4, MED29, MED23, MED12, and CDK8 and $C C N C$ did not substantially decrease androgen-stimulated probasinluciferase reporter activity in LNCaP cells. However, depletion of MED1, MED26, and MED14, MED15, and MED16 did decrease androgen-stimulated transcription of the reporter (Fig. 3A,B). Depletion of MED14, MED15, and MED16 also significantly reduced the proliferation of LNCaP-abl cells (Fig. 3C) but had no effect on AR-deficient PC3 prostate cancer cells, despite efficient depletion in both cell types (Fig. 3D; Supplemental Fig. 8). Reduction of MED4, MED12, and MED17 expression also affected LNCaP-abl cell proliferation but did not substantially affect AR-mediated transcription, suggesting that these subunits modulate cell proliferation independent of AR (Fig. 3A,C). Consistent with this interpretation, proliferation of PC3 cells was also reduced by depletion of MED17, MED4, and to a lesser extent by MED12 (Supplemental Fig. 8). Therefore, MED19, along with MED14, MED15, and MED16, affect both AR-mediated transcription and LNCaP-abl cell proliferation.

Like MED19, depletion of HIPK2 in LNCaP cells also affected the androgen-dependent expression of PSA and FKBP5, but had little effect on NKX3.1 (Fig. 4A). Importantly, depletion of HIPK2

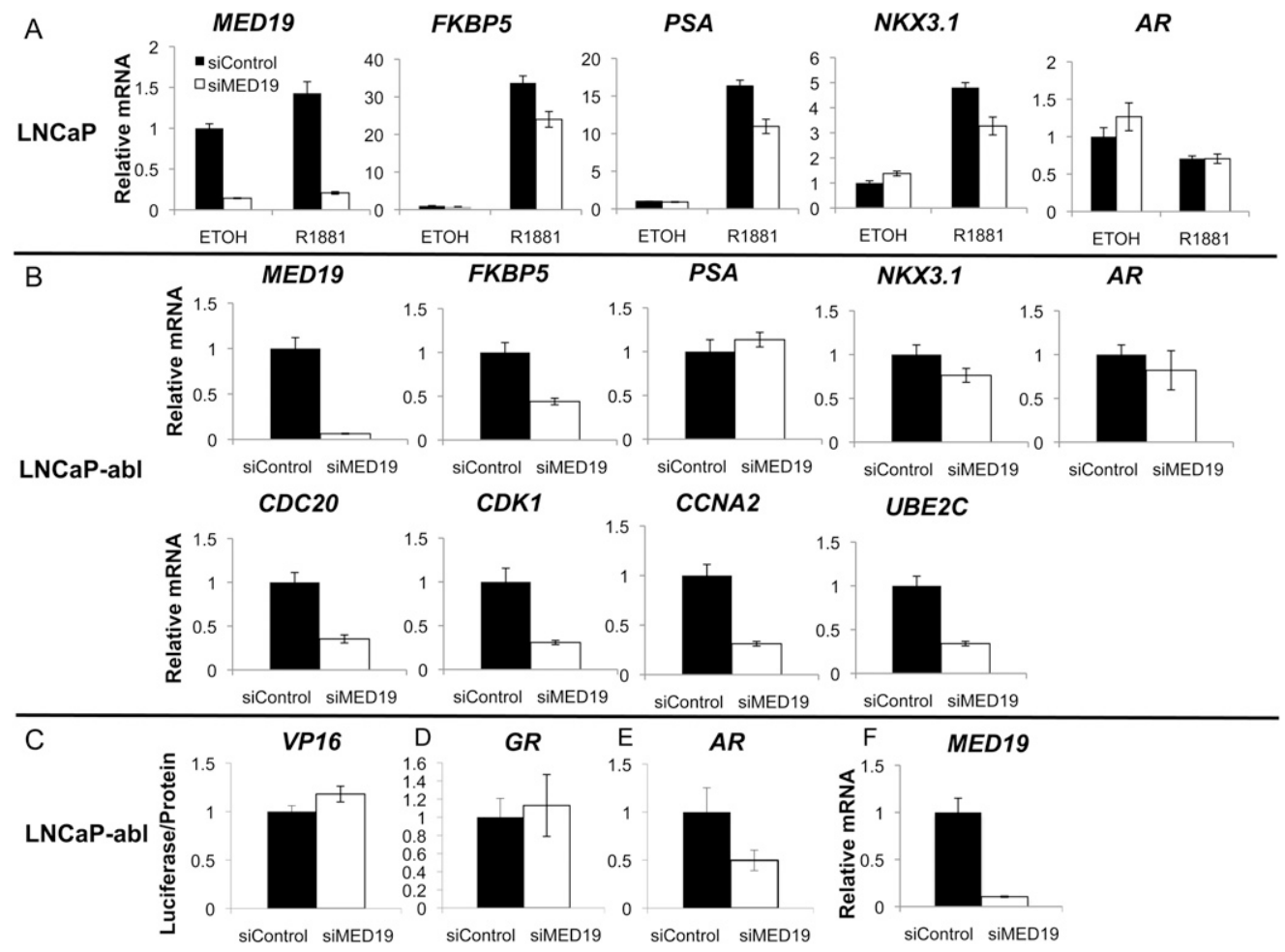

Figure 2. MED19 depletion affects AR target genes expression. MED19 knockdown decreases the expression of AR target genes in LNCaP $(A)$ and LNCaP-abl (B) cells. Cells were transfected with control (siControl) or MED19 siRNA (siMED19), and either androgen deprived for $48 \mathrm{~h}$ and then treated with $10 \mathrm{nM} \mathrm{R} 1881$ for $24 \mathrm{~h}$ (LNCaP) or cultured in media with $10 \%$ charcoal-stripped FBS for $48 \mathrm{~h}$ (LNCaP-abl). Relative mRNA levels of the indicated genes were analyzed by qPCR and normalized to RPL19. Each assay was performed in duplicate, with error bars representing the range of the mean. (C-F) MED19 selectively regulates AR transcriptional activity. LNCaP-abl cells were transfected with control siRNA (siControl) or siRNA against MED19 (siMED19) together with (C) a plasmid expressing the Gal4 DNA-binding domain fused to the VP16 activation domain, along with a luciferase reporter gene driven by five Gal4-binding sites upstream of the E1b promoter. $(D)$ A plasmid containing the human GR and a GR-responsive luciferase reporter, treated with $100 \mathrm{nM}$ dexamethasone. (E) An AR-responsive luciferase reporter treated with $10 \mathrm{nM} \mathrm{R1881.} \mathrm{Luciferase} \mathrm{activity} \mathrm{was} \mathrm{measured,} \mathrm{normalized} \mathrm{to} \mathrm{protein,} \mathrm{and} \mathrm{pre-}$ sented as RLU. $(F)$ The efficiency of MED19 knockdown was monitored at the mRNA level. Each assay was performed in triplicate, with error bars representing the standard deviation. The experiment was repeated twice with similar results.

\section{Genome Research}


A

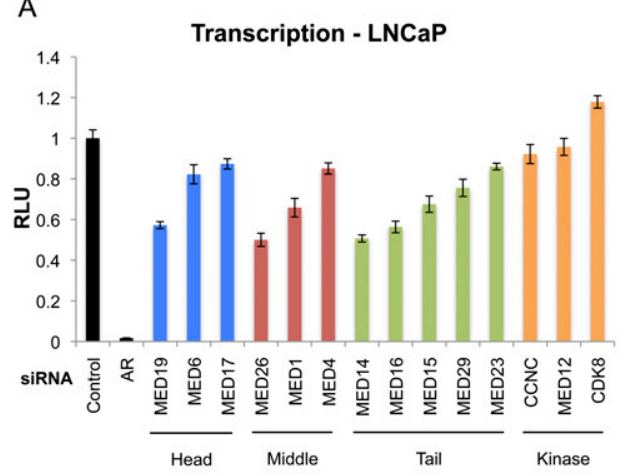

B

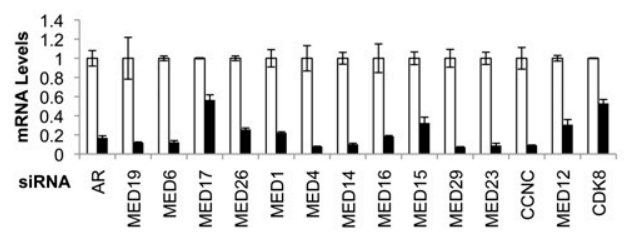

C

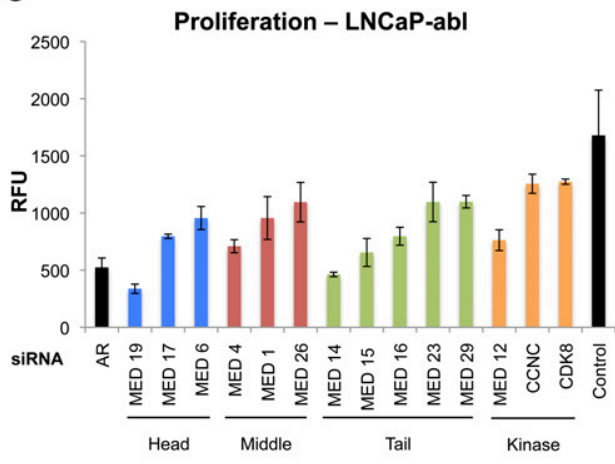

D

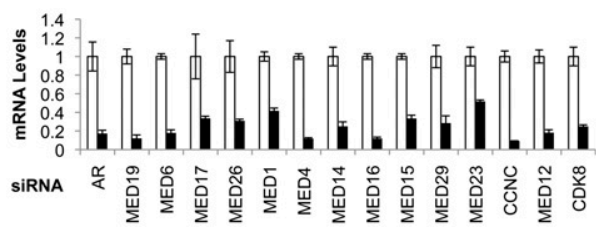

Figure 3. Mediator subunits differentially affect AR transcriptional activity and prostate cancer cell proliferation. (A) LNCaP cells stably expressing an AR-responsive probasin-luciferase reporter gene were transfected with siRNAs against the indicated Mediator complex subunits or a scrambled, nonsilencing siRNA (control) and, after $48 \mathrm{~h}$, were treated with $10 \mathrm{nM} \mathrm{R} 1881$ for $24 \mathrm{~h}$. Luciferase activity was measured and normalized to protein and presented as relative luminescence units (RLUs). (B) The efficiency of knockdown of each factor was determined at the mRNA level relative to RPL19 and shown as relative mRNA expression. (White bars) Nonsilencing siRNA; (black bars) the indicated siRNAs. (C) LNCaP-abl cells were transfected with siRNAs against the indicated Mediator complex subunits or a scrambled, nonsilencing siRNA (control), and cell proliferation was measured after $7 \mathrm{~d}$ as in Figure 1 . Data are shown as relative fluorescence units (RFUs). (D) Efficiency of knockdown at the mRNA level is shown relative to RPL19. (White bars) Nonsilencing siRNA; (black bars) the indicated siRNAs. Each assay was performed in triplicate, with error bars representing the standard deviation.

reduced the expression of the AR-target genes in $\mathrm{LNCaP}$-abl cells, including UBE2C, CDC2O, CDK1, and CCNA2, as well as reduced expression under basal conditions of FKBP5, PSA, but not NKX3.1 (Fig. 4B). In fact, both basal and androgen-dependent expression of CDK1 is affected by knockdown of HIPK2 and MED19, whereas hormone-dependent induction of FKBP5 is compromised by MED19 but not HIPK2 depletion (Supplemental Fig. 9), suggesting that the effect of HIPK2 on AR is gene specific and manifest under low hormone conditions. The reduction in gene expression of the cell cycle regulators CCNA2, CDC2O, UBE2C, and CDK1 could be interpreted as an indirect result of decreased cell cycle progression rather than a direct effect on AR activity. We think this is unlikely given that these genes have been shown to be controlled by AR in this cell line (Wang et al. 2009). In addition, there is only a small

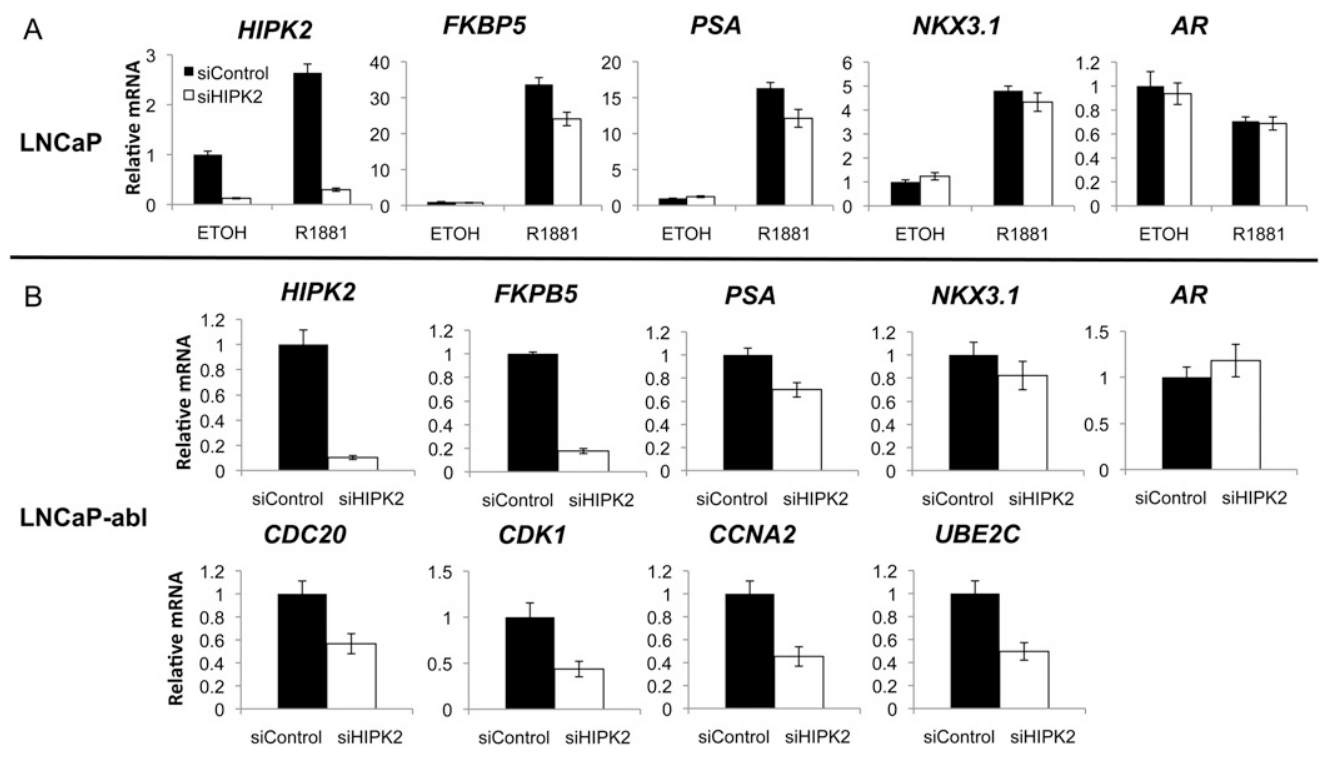

Figure 4. HIPK2 depletion affects AR target gene expression. HIPK2 knockdown decreases the expression of AR target genes in LNCaP $(A)$ and LNCaP$\mathrm{abl}(B)$ cells. Cells were transfected with control (siControl) or HIPK2 siRNA (siHIPK2) and either androgen deprived for $48 \mathrm{~h}$ and then treated with $10 \mathrm{nM}$ R1 881 for $24 \mathrm{~h}$ (LNCaP) or cultured in media with 10\% charcoal-stripped FBS for $48 \mathrm{~h}$ (LNCaP-abl). Relative mRNA levels of the indicated genes were analyzed by qPCR and normalized to RPL19. Each assay was performed in duplicate, with error bars representing the range of the mean. 
change in cell cycle distribution upon HIPK2 and MED19 depletion in LNCaP-abl cells after $24 \mathrm{~h}$ (Supplemental Fig. 10). Nevertheless, we cannot formally exclude the possibility that the cells have undergone changes not yet reflected in the cell cycle distribution that influence gene expression. Our results suggest that MED19 and HIPK 2 affect genes modulated by AR in CRPC cells.

We next generated genome-wide expression profiles of RNA extracted from LNCaP-abl cells depleted of MED19 or HIPK2 (Fig. 5A). This analysis identified 443 and 448 genes sensitive to MED19 and HIPK2, respectively (Fig. 5B). Of these genes, for MED19 there were 250 down-regulated and 193 up-regulated, while for HIPK2 there were 264 down-regulated and 184 up-regulated by $>1.5$-fold. From these, 41 genes for MED19 knockdown and 35 genes for HIPK2 knockdown were also changed upon depletion of $A R$ from LNCaP-abl cells (Fig. 5C; Supplemental Table 3). An interactive Venn diagram comparing the data sets is available at http:// sungear.bio.nyu.edu/imberg2013/ (Poultney et al. 2007). Gene Ontology (GO) analysis reveals that HIPK2 and MED19 control

A
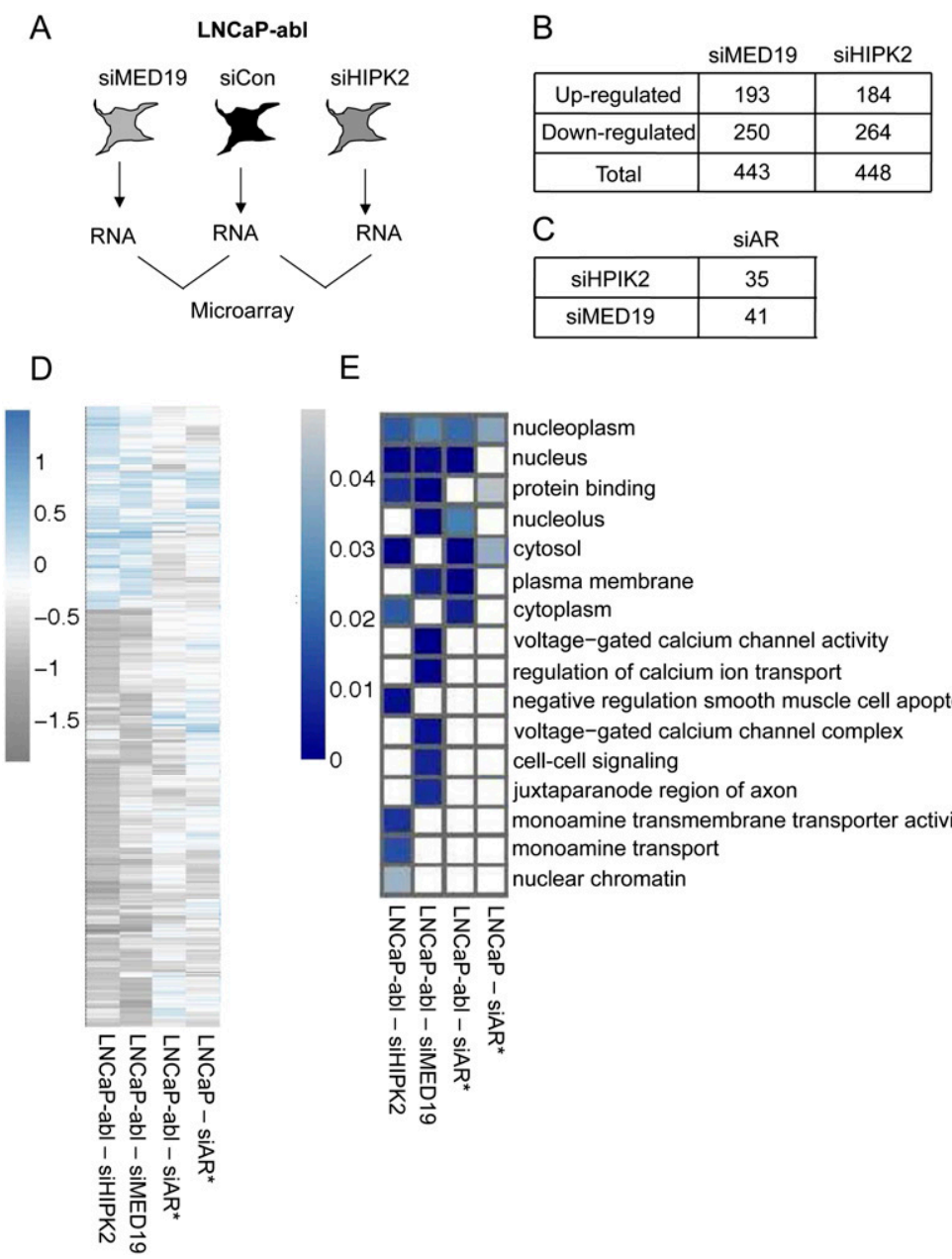

$\mathrm{E}$

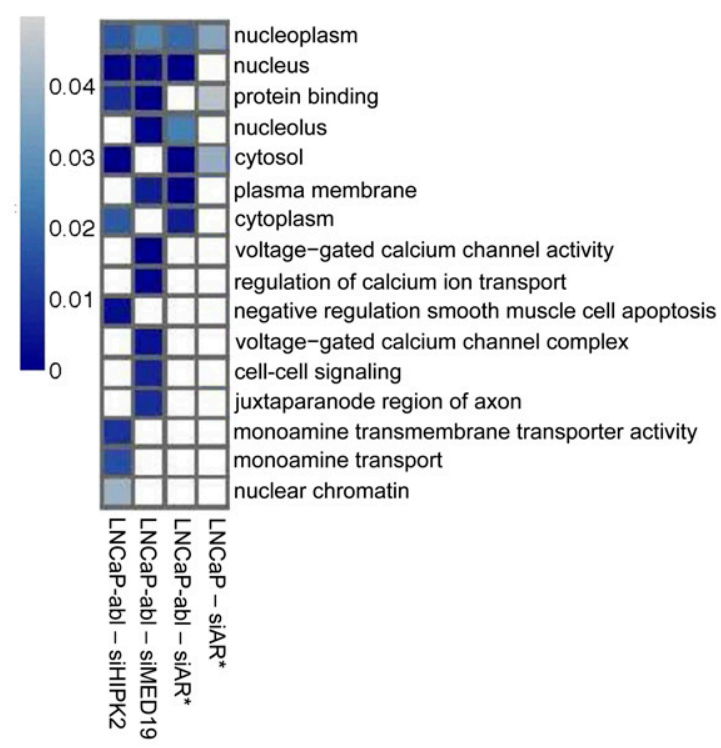

Figure 5. Effects of MED19 and HIPK2 depletion on gene expression in LNCaP-abl cells. $(A)$ Depiction of the procedure used to examine MED19 and HIPK2-responsive genes. (B) Number of genes up-regulated and down-regulated by $>1.5$-fold upon MED19 and HIPK2 depletion in LNCaP-abl cells. (C) Numbers of genes in MED19 and HIPK2 siRNA-depleted LNCaP-abl cells that overlap with siRNA knockdown of AR in LNCaP-abl cells. $(D)$ Microarray heat map of changes in gene expression in LNCaPabl cells depleted of HIPK2, MED19, AR, and parental LNCaP cells depleted of AR siRNA. (E) Gene Ontology analysis of the genes affected by siRNA depletion of the indicated factor in LNCaP-abl cells. $\left({ }^{*}\right)$ The data sets for LNCaP siAR, LNCaP-abl siAR were taken from Gene Expression Omnibus accession numbers GSE7868 and GSE11428 (Wang et al. 2009). genes in common with AR that are involved in regulating cellular components and biological processes in the nucleus, nucleoplasm, and in protein binding. GO classes that are not shared h AR for HIPK2 include monoamine transport and negative 作, whereas classes for MED19 distinct from AR comprise cell-cell signaling and regulation of calcium ion ort, as well as plasma membrane and nucleolus functions with AR function, while also regulating genes and pathways in-

\section{HIPK2 and MED19 depletion selectively affects proliferation} AR-expressing prostate cancer cells

Next, we examined the specificity and selectivity of HIPK2 and MED19 depletion on the proliferation of additional cell types, including AR-expressing, hormone-dependent LNCaP cells and AR-deficient PC3 prostate cancer cells, as well as an AR-negative embryonic kidney cell line, HEK293. Depletion of MED19 had a potent inhibitory effect on cell proliferation for both LNCaP and LNCaP-abl cells, but had no effect on the proliferation of PC3 or HEK293 cells, despite efficient reduction of MED19 expression by siRNA in these cell types. When HIPK2 was depleted, it too had a strong growth-inhibitory effect on LNCaP-abl cells and LNCaP cells, but had no effect on PC3 or HEK293 cell proliferation (Fig. 6A-D). Efficient depletion of HIPK2 expression by siRNA was observed in all cell lines (Fig. 6E-H). This demonstrates the specificity of both MED19 and HIPK2 in selectively regulating the proliferation of LNCaP and LNCaP-abl cells.

\section{Inhibitors of HIPK2 reduce the proliferation of AR-expressing prostate cancer cells and decrease AR target gene expression}

Since HIPK2 encodes protein kinase, we wanted to test the possibility of targeting it with a small-molecule inhibitor. Because there are no HIPK2-specific inhibitors commercially available, we turned to the broad-spectrum kinase inhibitor BAY 43-9006 (sorafenib), an FDA-approved drug, which has been shown to inhibit HIPK2 catalytic activity (Bain et al. 2007). Treatment of cells with BAY 43-9006 inhibited LNCaP and LNCaP-abl but not PC3 or HEK293 proliferation, recapitulating the phenotype observed by depletion of HIPK2 (Fig. 7A). We observed similar results with AS 601245, a broadrange kinase inhibitor that also inhibits HIPK2 (Supplemental Fig. 11; Bain et al. 2007).

We also compared the impact of BAY 43-9006 treatment with HIPK2 depletion

\section{Genome Research www.genome.org}



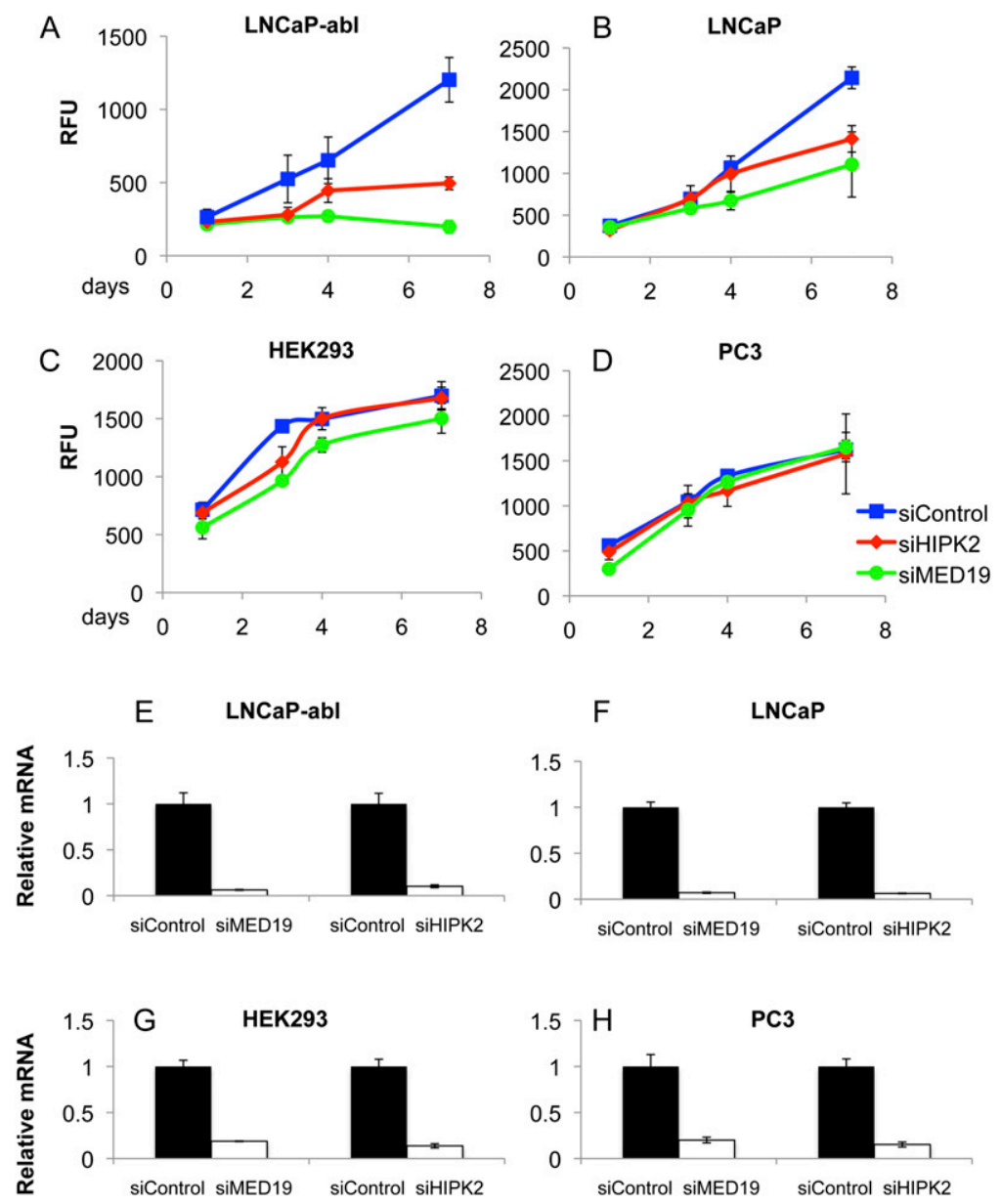

Figure 6. HIPK2 and MED19 depletion selectively affects the proliferation of AR-expressing prostate cancer cells. AR-positive prostate cancer cell lines $(A) \mathrm{LNCaP}$ and $(B) \mathrm{LNCaP}$-abl and AR-negative (C) HEK293 and (D) PC3 cells were transfected with control siRNA (siControl), HIPK2 siRNA (siHIPK2), or MED19 siRNA (siMED19), and cell proliferation was measured at the indicated days and shown as relative fluorescence units (RFUs). ( $E-H$ ) The efficiency of knockdown was monitored at the mRNA level for each factor in the four cell lines relative to RLP19. Each experiment was repeated at least two times. A representative experiment is shown.

on AR target gene expression in LNCaP-abl cells. As before, HIPK2 depletion inhibited the expression of FKPB5, CDK1, and UBE2C. Likewise, BAY 43-9006 treatment reduced the expression of these target genes (Fig. 7B). Treatment with BAY 43-9006 in the context of simultaneous reduction of HIPK2 did not further reduce the expression of the AR target genes, nor did it further reduce proliferation, suggesting that the effect of BAY 43-9006 is through HIPK2 in LNCaP-abl cells (Fig. 7B,C), and that a HIPK2 kinase inhibitor can target AR-dependent CRPC cells.

\section{Discussion}

We have conducted a genome-wide RNAi screen to seek genes required for AR-dependent transcriptional activity. We successfully identified AR regulators not previously linked to AR action, such as HIPK2 and MED19, and found that their inhibition modulated AR-dependent gene expression and reduced the proliferation of AR-expressing prostate cancer cells.

HIPK2 is a nuclear serine-threonine kinase that regulates gene expression by phosphorylating transcription factors and accessory components of the transcription machinery. In nontransformed cells, HIPK2 is activated by genotoxic stress, but in tumor cells, its activity appears constitutive (Rinaldo et al. 2007). Although shown to function as a tumor suppressor (Wei et al. 2007), HIPK2 also appears to function as an oncogene. In astrocytomas, the HIPK2 gene is frequently amplified (40\%-60\%), and HIPK2 overexpression stimulates cell growth (Deshmukh et al. 2008). Elevated HIPK2 protein levels in cervical cancer tissues is associated with tumor progression (AlBeiti and Lu 2008).

The mechanism of HIPK2 modulation of AR function is not understood. HIPK2 associates with EP300 and stimulates its HAT activity (Aikawa et al. 2006), which could regulate local histone and $\mathrm{AR}$ acetylation and the resulting transcription of AR target genes. HIPK2 modulates, through phosphorylation, the activity of both TCF and LEF family members (Hikasa and Sokol 2011), which in concert with beta-catenin regulates $\mathrm{AR}$ expression (Li et al. 2009). HIPK2 could also phosphorylate AR to modulate its function, because there are nine potential sites of HIPK2 phosphorylation on AR.

We have shown that blocking HIPK2 activity using kinase inhibitors had a similar effect on AR target gene expression and proliferation of AR-expressing prostate cancer cells as depletion of HIPK2 by siRNA. This suggests that that the kinase activity of HIPK2 is important for the effect, and that specific targeting of HIPK2, which has been recently attempted and lead compounds identified via high-throughput kinase profiling (Miduturu et al. 2011), could have therapeutic value for prostate cancer patients where HIPK2 is activated. In fact, sorafenib has shown moderate activity as a second-line treatment for CRPC (Aragon-Ching et al. 2009), and our findings suggest that stratifying patients for HIPK2 up-regulation could enhance sorafenib efficacy.

We identified MED19 as an AR regulator that inhibits AR-dependent transcription and proliferation of AR-expressing prostate cancer cells. Notably, changes in MED19 appear to be linked to a poor prognosis (Supplemental Fig. 5). The Mediator is an $\sim 30$ subunit complex that acts as a bridge between transcription factors and RNA polymerase II to affect transcription initiation (Malik and Roeder 2010) and elongation (Takahashi et al. 2011). The Mediator complex has been divided into a head, middle, and tail regions as well as a kinase module. The tail region mediates activator interactions, while the head region interacts with components of RNA polymerase II. MED19 is located in the head region, whereas subunits MED14, MED15, and MED16 are located at the tail. Depletion of these subunits affected AR transcriptional activity and proliferation. It is conceivable that MED19 is directly associating with AR to affect receptor-mediated transcription. In fact, we find an association between MED19 and AR as judged by coimmunoprecipitation (Supplemental Fig. 7). Alternatively, MED19 
A

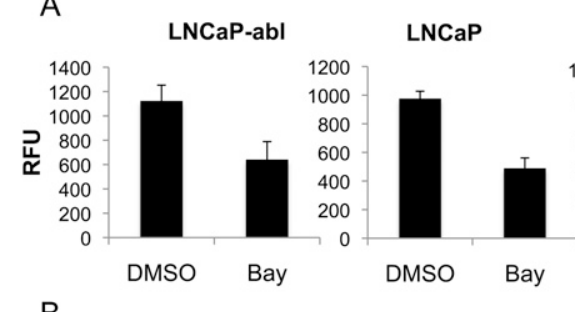

$\mathrm{PC} 3$

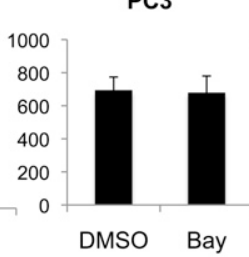

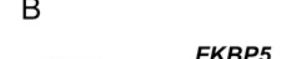
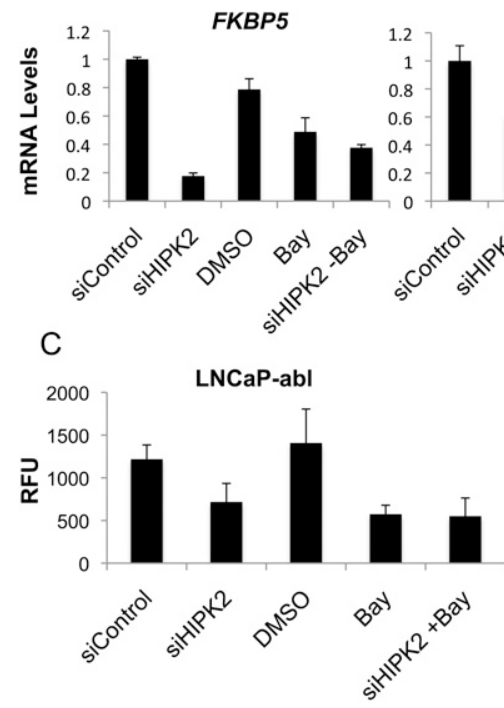

Figure 7. A kinase inhibitor to HIPK2 recapitulates the effects of HIPK2 depletion on prostate cancer cell proliferation and AR target genes expression. (A) LNCaP-abl, LNCaP, PC3, and HEK293 cells were treated with $5 \mu \mathrm{M}$ BAY 43-9006, and cell proliferation was measured after $4 \mathrm{~d}$. Data are shown as relative fluorescence units (RFUs). (B) LNCaP-abl cells were treated with $5 \mu \mathrm{M}$ BAY 43-9006 or vehicle (DMSO) in the presence (siControl) or absence of HIPK2 (siHIPK2), and the mRNA levels of AR target genes FKBP5, CDK1, and UBEC2 were measured by qPCR relative to RPL19. (C) Impact of BAY 43-9006 treatment on LNCaP-abl cell proliferation as a function of HIPK2. LNCaP-abl cells were depleted of HIPK2 as in $B$, and cell proliferation was measured after $7 \mathrm{~d}$ in the absence (DMSO) and presence of $5 \mu \mathrm{M}$ BAY 43-9006. Each experiment was performed at least two times with similar results.

might promote interactions between the head and tail regions (Baidoobonso et al. 2007), with AR associating with MED14, MED15, and/or MED16 (Sharma et al. 2013). MED19 has also been shown to play a role in transcriptional elongation since deletion of the yeast homolog affects the induction of the Hsc82 gene by reducing RNA polymerase II occupancy throughout the body of the gene (Kremer et al. 2012).

We also identified MED17, MED4, and to a lesser extent MED12 as subunits that when depleted, affected both LNCaP-abl and PC3 proliferation. These subunits are likely involved in controlling genes affecting cellular proliferation both dependent and independent of AR. Consistent with this finding is the modest effect on AR-dependent transcriptional activation. Recent exome sequencing of prostate cancers revealed frequent mutations in MED12 (Barbieri et al. 2012). In addition to its nuclear activity, MED12 has recently been shown to function in the cytoplasm to negatively regulate TGF- $\beta$ receptor signaling such that loss of MED12 results in enhanced TGF- $\beta$ signaling and drug resistance in models of colon and lung cancer (Huang et al. 2012). Whether the nuclear or cytoplasmic function of MED12 is affected by the mutations found in prostate cancers remains an open question.

Other siRNA screens have been reported that used decreased LNCaP cell proliferation rather than AR transcriptional activity as

\section{RNAi screen}

HEK293

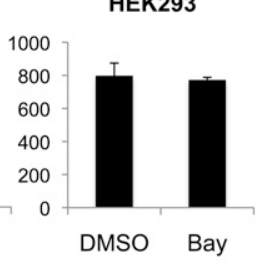

the phenotypic end point (Dahlman et al. 2012; Whitworth et al. 2012). Interestingly, the factors identified in these screens and ours were largely nonoverlapping, suggesting that the screens were subsaturating and/or different end-point assays uncover unique factors affecting prostate cancer proliferation.

In summary, using an unbiased genetic approach, we have identified new $\mathrm{AR}$ regulators and further validated the use of cross-species screening in Drosophila cells to elucidate complex pathways in human cells. Identification of the kinase HIPK2 afforded a small molecule inhibitor approach that recapitulated the effects on growth and gene expression as siRNA depletion of HIPK2, auguring a potential therapeutic target. Due to the unexpected intensity of MED19's effect on prostate cancer cell proliferation, the selectivity toward AR regulation, as well as its deregulation being associated with poor patient outcome also make it an intriguing target to fight prostate cancer by silencing its expression.

\section{Methods}

\section{Cell culture}

LNCaP, HEK293, and PC3 cell lines were purchased from the ATCC (Manassas, VA). LNCaP-abl cells were from Zoran Culig (Innsbruck Medical University, Austria). LNCaP and LNCaP-abl cells were maintained in RPMI-1640, HEK293 were cultured in DMEM, and PC3 cells were grown in Ham's F12 (Cellgro; Mediatech, Inc.). The above media was supplemented with $10 \%$ fetal bovine serum (FBS) (Hyclone; Thermo Fisher Scientific) and $1 \%$ penicillin-streptomycin and 1\% L-Glutamine (Cellgro; Mediatech, Inc.), LNCaP-abl cells were cultured in RPMI-1640 without phenol red media (Cellgro; Mediatech, Inc.) supplemented with 10\% charcoal-stripped fetal bovine serum (cFBS), 1\% penicillinstreptomycin, and 1\% L-glutamine.

The Whole Genome Drosophila Library (DRSC 2.0) contains 13,900 genes, with an average of one to two dsRNAs per gene, with each dsRNA aliquoted into a single well of a 384-well plate. Drosophila S2R+ cells $(20,000)$ were reverse-transfected using the Effectene transfection reagent (QIAGEN) with pMK33-hAR (80 ng), pARE3-Firefly luciferase (50 ng), and PolIII-Renilla luciferase (30 $\mathrm{ng}$ ) of plasmid DNA/well. Plates were incubated for $48 \mathrm{~h}$ at $25^{\circ} \mathrm{C}$ before treatment with $10 \mathrm{nM}$ R1881 for an additional $24 \mathrm{~h}$. To measure AR transcriptional activity, the Dual Glo Luciferase Assay (Promega) was performed and read using the Envision Multilabel Plate Reader (PerkinElmer); the firefly luciferase was normalized to the Renilla luciferase levels. The screen was performed in duplicate, and data were analyzed using multiple statistical protocols to identify the "hits" (Supplemental Methods). Genes showing a reduction of threefold of the control 
(GFP) average or a threefold increase from the control average were considered potential hits.

The same protocol for the genome-wide screen was used to screen the kinase and phosphatase library, which consists of 468 genes, with an average of three dsRNAs per gene, except that the control gene was beta-galactosidase (LacZ) dsRNA rather than GFP. For the data analysis, we used the same statistical parameters as described. A gene was included as a hit if it met two statistical parameters (see the Supplemental Methods for a description of the statistical methods used).

\section{Secondary validation screen}

The 249 amplicons chosen for the secondary screen (Supplemental Table 4) were first generated as dsRNAs from PCR products (received from the NYU RNAi Core Facility). Amplification by PCR was followed by in vitro transcription reactions of the CDNA PCR products into dsRNA using the Ambion MEGAscript T7, T3, and SP6 kits (Life Technologies).

The secondary screen was designed to include 83 amplicons and 13 controls per 96-well plate. Controls included AR-siRNA (positive control: lack of AR activity), GFP dsRNA (negative control: full AR transcriptional activation), and empty wells (gauge nonspecific effects of the siRNA on transcriptional activity). The transcriptional activity of the glucocorticoid receptor (GR) was assayed using a human GR construct (pMK33-hGR), and the same reporter gene was used for screening AR (the response elements in the reporter are the same for AR and GR). Cells were treated with vehicle (ethanol), $10 \mathrm{nM} \mathrm{R} 1881$ for AR, or $100 \mathrm{nM}$ dexamethasone (Dex) for GR. The secondary screen was performed and FL/RL was measured for both AR and GR under basal and hormone-induced conditions. AR-specific hits were defined as a twofold (high specificity) and a 1.5-fold (moderate specificity) difference between AR and GR activity.

\section{RNA interference in mammalian cells}

Three individual siRNAs (Silencer Select; Ambion, Life Technologies) were pooled and transfected into cells using the HiPerFect transfection reagent (QIAGEN) following the manufacturer's instructions. Nonsilencing siRNAs were used as controls. siRNAs were used at a final concentration of $25-30 \mathrm{nM}$ per individual siRNA.

\section{Luciferase assay}

Plates (24-well) were coated with poly-D-lysine for $2 \mathrm{~h}$ at $37^{\circ} \mathrm{C}$. LNCaP cells stably expressing an AR-responsive probasin-luciferase reporter gene (gift from Karen Knudsen) were seeded in triplicate at a density of $\sim 75,000$ cells/well in RPMI media supplemented with $10 \%$ FBS and transfected on two consecutive days with siRNAs as described above. Cells were steroid-starved by placing in phenol red-free RPMI media with $10 \%$ cFBS for $48 \mathrm{~h}$, then treated with $10 \mathrm{nM}$ R1881 for $24 \mathrm{~h}$. Luciferase activity was measured using $1 \times$ Passive Lysis Buffer (Promega) and assayed as described by the manufacturer. Data were normalized to protein concentration using the Bradford assay (Bio-Rad).

For luciferase assays in LNCaP-abl cells, cells were plated in media supplemented with $10 \%$ cFBS and transfected with siRNAs as above and cultured for $48 \mathrm{~h}$. For the GR activity assays, cells were treated with $100 \mathrm{nM}$ dexamethasone for $4 \mathrm{~h}$ before lysis.

\section{Proliferation assay}

Cells were plated in their appropriate growth media in triplicate (5000 cells/well for LNCaP and LNCaP-abl, 3000 cells/well for
HEK293 and PC3) in 96-well plates and reverse-transfected with a pool of three siRNAs using the HiPerFect transfection reagent as described above. Cell proliferation was determined using the Cyquant-NF Cell Proliferation Assay (Invitrogen), which quantifies the amount of fluorescent dye incorporated into newly synthesized DNA. Fluorescence was quantified at 485/530 nm with the SpectraMaxM5 Microplate Reader and SoftMaxPro software (Molecular Devices).

\section{RNA preparation and $\mathrm{qPCR}$}

Total RNA was isolated from cells using the RNeasy Mini Kit (QIAGEN). cDNA was synthesized using the First-Strand cDNA Synthesis Kit (USB) or SuperScript III reverse transcriptase (Invitrogen) and random primer hexamers following the manufacturers' instructions. Gene-specific cDNA was amplified in a $25-\mu \mathrm{L}$ reaction containing Hot Start SYBR Green qPCR Master Mix (USB). Realtime PCR was performed using the MyiQ Single-Color Real-Time PCR Detection System (Bio-Rad). Analysis was performed using the $\Delta \Delta$ CT method (Bookout et al. 2006), and RPL19 was used as an internal control for data normalization. The sequences of the primers used for real-time PCR are given in Supplemental Table 5.

\section{Cell cycle analysis}

LNCaP-abl cells cultured in 10\% CFBS media were transfected with siRNAs. After transfection $(24 \mathrm{~h})$, cells were trypsinized and fixed in $70 \%$ ethanol at $4^{\circ} \mathrm{C}$. Cells were then stained with $100 \mathrm{mg} / \mathrm{mL}$ propidium iodide and processed for flow cytometry (Becton-Dickinson FACScalibur). Data were analyzed using FlowJo software.

\section{Microarray analysis}

Microarray experiments were carried out using Affymetrix Human Genome U133 plus 2.0 expression arrays on RNA from LNCaP-abl cells transfected with control siRNA, MED19 siRNA, or HIPK2 siRNA. Normalization of the raw data and calculation of Gene Ontology enrichment and fold-changes were conducted using R BioConductor and the affy data processing package (Gautier et al. 2004; Gentleman et al. 2004). In addition to the microarray data generated in this study, publicly available data (Gene Expression Omnibus accession numbers GSE7868 and GSE11428) were used in the analysis (Wang et al. 2009). The Sungear software system was used to support the analysis and visualization of the gene expression data sets (Poultney et al. 2007). Genes and attendant GO annotations from LNCaP-abl siHIPK2, siMED19, siAR, and LNCaP siAR data sets were loaded into the system to yield the interactive Venn diagrams.

\section{Data access}

Results from the primary siRNA screen have been deposited with the Drosophila RNAi Screening Center (DRSC) (http://www.flyrnai. org) under the title "Factors affecting human androgen receptor transcriptional activation" (see Supplemental Table 4 for DRSC ID numbers). Microarray data are available through the NCBI Gene Expression Omnibus (GEO) (http://www.ncbi.nlm.nih.gov/geo/) under the accession number GSE43881.

\section{Acknowledgments}

This work was supported by the NIH (CA112226 to S.K.L.; CA143907 and EY016586 to R.B.), departmental funds from Dr. Claudio Basilico (Microbiology), Dr. Herbert Lepor (Urology), and from the NYU School of Medicine Centers of Excellence program. 
We thank Dr. Chi Yun, Dr. Ram DasGupta, and the NYU RNAi facility for technical support. Rachel Ruoff adeptly performed staining of HIPK2 from a prostate cancer tissue microarray obtained from the Prostate Cancer Biorepostiory Network. Dr. Karen Knudsen and Dr. Zoran Culig generously provided the LNCaP probasin-luciferase reporter and LNCaP-abl cells, respectively. We also thank members of the Garabedian and Logan laboratories for their critical assessment of the manuscript.

\section{References}

Aikawa Y, Nguyen LA, Isono K, Takakura N, Tagata Y, Schmitz ML, Koseki H Kitabayashi I. 2006. Roles of HIPK1 and HIPK2 in AML1- and p300dependent transcription, hematopoiesis and blood vessel formation. EMBO J 25: 3955-3965.

Al-Beiti MA, Lu X. 2008. Expression of HIPK2 in cervical cancer: Correlation with clinicopathology and prognosis. Aust N Z J Obstet Gynaecol 48: 329-336.

Aragon-Ching JB, Jain L, Gulley JL, Arlen PM, Wright JJ, Steinberg SM, Draper D, Venitz J, Jones E, Chen CC, et al. 2009. Final analysis of a phase II trial using sorafenib for metastatic castration-resistant prostate cancer. BJU Int 103: $1636-1640$.

Baidoobonso SM, Guidi BW, Myers LC. 2007. Med19(Rox3) regulates intermodule interactions in the Saccharomyces cerevisiae Mediator complex. J Biol Chem 282: 5551-5559.

Bain J, Plater L, Elliott M, Shpiro N, Hastie CJ, McLauchlan H, Klevernic I, Arthur JS, Alessi DR, Cohen P. 2007. The selectivity of protein kinase inhibitors: A further update. Biochem J 408: 297-315.

Ball JR, Ullman KS. 2005. Versatility at the nuclear pore complex: Lessons learned from the nucleoporin Nup153. Chromosoma 114: 319-330.

Barbieri CE, Baca SC, Lawrence MS, Demichelis F, Blattner M, Theurillat JP White TA, Stojanov P, Van Allen E, Stransky N, et al. 2012. Exome sequencing identifies recurrent SPOP, FOXA1 and MED12 mutations in prostate cancer. Nat Genet 44: 685-689.

Bedford FK, Ashworth A, Enver T, Wiedemann LM. 1993. HEX: A novel homeobox gene expressed during haematopoiesis and conserved between mouse and human. Nucleic Acids Res 21: 1245-1249.

Bjarnadottir TK, Fredriksson R, Schioth HB. 2005. The gene repertoire and the common evolutionary history of glutamate, pheromone (V2R), taste(1) and other related G protein-coupled receptors. Gene 362: 70-84

Bookout AL, Cummins CL, Mangelsdorf DJ, Pesola JM, Kramer MF. 2006. High-throughput real-time quantitative reverse transcription PCR. Curr Protoc Mol Biol 73: 15.8.1-15.8.28.

Chang CY, McDonnell DP. 2005. Androgen receptor-cofactor interactions as targets for new drug discovery. Trends Pharmacol Sci 26: 225-228.

Chen CD, Welsbie DS, Tran C, Baek SH, Chen R, Vessella R, Rosenfeld MG Sawyers CL. 2004. Molecular determinants of resistance to antiandrogen therapy. Nat Med 10: 33-39.

Chen W, Rogatsky I, Garabedian MJ. 2006. MED14 and MED1 differentially regulate target-specific gene activation by the glucocorticoid receptor. Mol Endocrinol 20: 560-572.

Chiu YT, Han HY, Leung SC, Yuen HF, Chau CW, Guo Z, Qiu Y, Chan KW, Wang X, Wong YC, et al. 2009. CDC25A functions as a novel Ar corepressor in prostate cancer cells. J Mol Biol 385: 446-456.

Comuzzi B, Lambrinidis L, Rogatsch H, Godoy-Tundidor S, Knezevic N, Krhen I, Marekovic Z, Bartsch G, Klocker H, Hobisch A, et al. 2003. The transcriptional co-activator cAMP response element-binding protein-binding protein is expressed in prostate cancer and enhances androgen- and anti-androgen-induced androgen receptor function. Am J Pathol 162: 233-241.

Culig Z, Hoffmann J, Erdel M, Eder IE, Hobisch A, Hittmair A, Bartsch G, Utermann G, Schneider MR, Parczyk K, et al. 1999. Switch from antagonist to agonist of the androgen receptor bicalutamide is associated with prostate tumour progression in a new model system. Br J Cancer 81: 242-251.

Cunha GR, Donjacour A. 1987. Stromal-epithelial interactions in normal and abnormal prostatic development. Prog Clin Biol Res 239: 251-272.

Dahlman KB, Parker JS, Shamu T, Hieronymus H, Chapinski C, Carver B Chang K, Hannon GJ, Sawyers CL. 2012. Modulators of prostate cance cell proliferation and viability identified by short-hairpin RNA library screening. PLOS ONE 7: e34414.

DasGupta R, Nybakken K, Booker M, Mathey-Prevot B, Gonsalves F, Changkakoty B, Perrimon N. 2007. A case study of the reproducibility of transcriptional reporter cell-based RNAi screens in Drosophila. Genome Biol 8: R203.

Dehm SM, Tindall DJ. 2007. Androgen receptor structural and functional elements: Role and regulation in prostate cancer. Mol Endocrinol 21: 2855-2863.
Deshmukh H, Yeh TH, Yu J, Sharma MK, Perry A, Leonard JR, Watson MA, Gutmann DH, Nagarajan R. 2008. High-resolution, dual-platform aCGH analysis reveals frequent HIPK2 amplification and increased expression in pilocytic astrocytomas. Oncogene 27: 4745-4751.

Echeverri CJ, Perrimon N. 2006. High-throughput RNAi screening in cultured cells: A user's guide. Nat Rev Genet 7: 373-384

Fu M, Wang C, Reutens AT, Wang J, Angeletti RH, Siconolfi-Baez L, Ogryzko V, Avantaggiati ML, Pestell RG. 2000. p300 and p300/cAMP-response element-binding protein-associated factor acetylate the androgen receptor at sites governing hormone-dependent transactivation. J Biol Chem 275: 20853-20860.

Gao J, Arnold JT, Isaacs JT. 2001. Conversion from a paracrine to an autocrine mechanism of androgen-stimulated growth during malignant transformation of prostatic epithelial cells. Cancer Res 61: 5038-5044.

Gautier L, Cope L, Bolstad BM, Irizarry RA. 2004. affy-analysis of Affymetrix GeneChip data at the probe level. Bioinformatics 20: 307-315.

Gentleman RC, Carey VJ, Bates DM, Bolstad B, Dettling M, Dudoit S, Ellis B, Gautier L, Ge Y, Gentry J, et al. 2004. Bioconductor: Open software development for computational biology and bioinformatics. Genome Biol 5: R80.

Hadjantonakis AK, Sheward WJ, Harmar AJ, de Galan L, Hoovers JM, Little PF. 1997. Celsr1, a neural-specific gene encoding an unusual seven-pass transmembrane receptor, maps to mouse chromosome 15 and human chromosome 22qter. Genomics 45: 97-104.

Heemers HV, Tindall DJ. 2007. Androgen receptor (AR) coregulators: A diversity of functions converging on and regulating the AR transcriptional complex. Endocr Rev 28: 778-808.

Hikasa H, Sokol SY. 2011. Phosphorylation of TCF proteins by homeodomain-interacting protein kinase 2. J Biol Chem 286: 12093-12100.

Hittelman AB, Burakov D, Iniguez-Lluhi JA, Freedman LP, Garabedian MJ. 1999. Differential regulation of glucocorticoid receptor transcriptional activation via AF-1-associated proteins. EMBO J 18: 5380-5388.

Huang S, Holzel M, Knijnenburg T, Schlicker A, Roepman P, McDermott U, Garnett M, Grernrum W, Sun C, Prahallad A, et al. 2012. MED12 controls the response to multiple cancer drugs through regulation of TGF- $\beta$ receptor signaling. Cell 151: 937-950.

Hunger SP, Ohyashiki K, Toyama K, Cleary ML. 1992. Hlf, a novel hepatic bZIP protein, shows altered DNA-binding properties following fusion to E2A in $\mathrm{t}(17 ; 19)$ acute lymphoblastic leukemia. Genes Dev 6: 1608-1620.

Inagaki N, Mizuta M, Seino S. 1994. Cloning of a mouse Rabphilin-3A expressed in hormone-secreting cells. J Biochem 116: 239-242.

Ito M, Yuan CX, Malik S, Gu W, Fondell JD, Yamamura S, Fu ZY, Zhang X, Qin J, Roeder RG. 1999. Identity between TRAP and SMCC complexes indicates novel pathways for the function of nuclear receptors and diverse mammalian activators. Mol Cell 3: 361-370.

Kenmochi N, Suzuki T, Uechi T, Magoori M, Kuniba M, Higa S, Watanabe K, Tanaka T. 2001. The human mitochondrial ribosomal protein genes: Mapping of 54 genes to the chromosomes and implications for human disorders. Genomics 77: 65-70.

Kremer SB, Kim S, Jeon JO, Moustafa YW, Chen A, Zhao J, Gross DS. 2012 Role of Mediator in regulating Pol II elongation and nucleosome displacement in Saccharomyces cerevisiae. Genetics 191: 95-106.

Li Y, Wang L, Zhang M, Melamed J, Liu X, Reiter R, Wei J, Peng Y, Zou X, Pellicer A, et al. 2009. LEF1 in androgen-independent prostate cancer: Regulation of androgen receptor expression, prostate cancer growth and invasion. Cancer Res 69: 3332-3338.

Link KA, Burd CJ, Williams E, Marshall T, Rosson G, Henry E, Weissman B Knudsen KE. 2005. BAF57 governs androgen receptor action and androgen-dependent proliferation through SWI/SNF. Mol Cell Biol 25: 2200-2215.

Lupien M, Eeckhoute J, Meyer CA, Wang Q, Zhang Y, Li W, Carroll JS, Liu XS Brown M. 2008. FoxA1 translates epigenetic signatures into enhancerdriven lineage-specific transcription. Cell 132: $958-970$.

Malik S, Roeder RG. 2010. The metazoan Mediator co-activator complex as an integrative hub for transcriptional regulation. Nat Rev Genet 11: 761-772.

Miduturu CV, Deng X, Kwiatkowski N, Yang W, Brault L, Filippakopoulos P, Chung E, Yang Q, Schwaller J, Knapp S, et al. 2011. High-throughput kinase profiling: A more efficient approach toward the discovery of new kinase inhibitors. Chem Biol 18: 868-879.

Muller JM, Isele U, Metzger E, Rempel A, Moser M, Pscherer A, Breyer T, Holubarsch C, Buettner R, Schule R. 2000. FHL2, a novel tissue-specific coactivator of the androgen receptor. EMBO J 19: 359-369.

Nabhan C, Parsons B, Touloukian EZ, Stadler WM. 2011. Novel approaches and future directions in castration-resistant prostate cancer. Ann Oncol 22: $1948-1957$.

Ngan ES, Hashimoto Y, Ma ZQ, Tsai MJ, Tsai SY. 2003. Overexpression of Cdc25B, an androgen receptor coactivator, in prostate cancer. Oncogene 22: $734-739$.

\section{Genome Research}


Norris JD, Joseph JD, Sherk AB, Juzumiene D, Turnbull PS, Rafferty SW, Cui H, Anderson E, Fan D, Dye DA, et al. 2009. Differential presentation of protein interaction surfaces on the androgen receptor defines the pharmacological actions of bound ligands. Chem Biol 16: 452-460.

Peelman LJ, Chardon P, Nunes M, Renard C, Geffrotin C, Vaiman M, Van Zeveren A, Coppieters W, van de Weghe A, Bouquet Y, et al. 1995. The BAT1 gene in the MHC encodes an evolutionarily conserved putative nuclear RNA helicase of the DEAD family. Genomics 26: 210-218.

Persson A, Hober S, Uhlen M. 2006. A human protein atlas based on antibody proteomics. Curr Opin Mol Ther 8: 185-190.

Poultney CS, Gutierrez RA, Katari MS, Gifford ML, Paley WB, Coruzzi GM, Shasha DE. 2007. Sungear: Interactive visualization and functional analysis of genomic datasets. Bioinformatics 23: 259-261.

Raben DM, Tu-Sekine B. 2008. Nuclear diacylglycerol kinases: Regulation and roles. Front Biosci 13: 590-597.

Rinaldo C, Prodosmo A, Siepi F, Soddu S. 2007. HIPK2: A multitalented partner for transcription factors in DNA damage response and development. Biochem Cell Biol 85: 411-418.

Sagara J, Higuchi T, Hattori Y, Moriya M, Sarvotham H, Shima H, Shirato H, Kikuchi K, Taniguchi S. 2003. Scapinin, a putative protein phosphatase-1 regulatory subunit associated with the nuclear nonchromatin structure. J Biol Chem 278: 45611-45619.

Sagara J, Arata T, Taniguchi S. 2009. Scapinin, the protein phosphatase 1 binding protein, enhances cell spreading and motility by interacting with the actin cytoskeleton. PLoS ONE 4: e4247.

Sharma NL, Massie CE, Ramos-Montoya A, Zecchini V, Scott HE, Lamb AD, Macarthur S, Stark R, Warren AY, Mills IG, et al. 2013. The androgen receptor induces a distinct transcriptional program in castrationresistant prostate cancer in man. Cancer Cell 23: 35-47.

Siu YT, Jin DY. 2007. CREB-a real culprit in oncogenesis. FEBS J 274: 3224-3232.

Sreekumar A, Poisson LM, Rajendiran TM, Khan AP, Cao Q, Yu J, Laxman B, Mehra R, Lonigro RJ, Li Y, et al. 2009. Metabolomic profiles delineate potential role for sarcosine in prostate cancer progression. Nature 457: 910-914.

Takagaki Y, Manley JL. 1997. RNA recognition by the human polyadenylation factor CstF. Mol Cell Biol 17: 3907-3914.
Takahashi H, Parmely TJ, Sato S, Tomomori-Sato C, Banks CA, Kong SE, Szutorisz H, Swanson SK, Martin-Brown S, Washburn MP, et al. 2011. Human mediator subunit MED26 functions as a docking site for transcription elongation factors. Cell 146: 92-104.

Taylor BS, Schultz N, Hieronymus H, Gopalan A, Xiao Y, Carver BS, Arora VK, Kaushik P, Cerami E, Reva B, et al. 2010. Integrative genomic profiling of human prostate cancer. Cancer Cell 18: 11-22.

Wahlstrom T, Henriksson M. 2007. Mnt takes control as key regulator of the myc/max/mxd network. Adv Cancer Res 97: 61-80.

Wang L, Lin HK, Hu YC, Xie S, Yang L, Chang C. 2004. Suppression of androgen receptor-mediated transactivation and cell growth by the glycogen synthase kinase $3 \beta$ in prostate cells. J Biol Chem 279: 32444-32452.

Wang Q, Li W, Zhang Y, Yuan X, Xu K, Yu J, Chen Z, Beroukhim R, Wang H, Lupien $M$, et al. 2009. Androgen receptor regulates a distinct transcription program in androgen-independent prostate cancer. Cell 138: 245-256.

Wei G, Ku S, Ma GK, Saito S, Tang AA, Zhang J, Mao JH, Appella E, Balmain A, Huang EJ. 2007. HIPK2 represses $\beta$-catenin-mediated transcription, epidermal stem cell expansion, and skin tumorigenesis. Proc Natl Acad Sci 104: 13040-13045.

Whitworth H, Bhadel S, Ivey M, Conaway M, Spencer A, Hernan R, Holemon H, Gioeli D. 2012. Identification of kinases regulating prostate cancer cell growth using an RNAi phenotypic screen. PLOS ONE 7: e38950.

Yang Z, Chang YJ, Miyamoto H, Yeh S, Yao JL, di Sant'Agnese PA, Tsai MY, Chang C. 2007. Suppression of androgen receptor transactivation and prostate cancer cell growth by heterogeneous nuclear ribonucleoprotein A1 via interaction with androgen receptor coregulator ARA54. Endocrinology 148: 1340-1349.

Yoshinaga SK, Yamamoto KR. 1991. Signaling and regulation by a mammalian glucocorticoid receptor in Drosophila cells. Mol Endocrinol 5: $844-853$.

Received June 18, 2012; accepted in revised form January 31, 2013. 


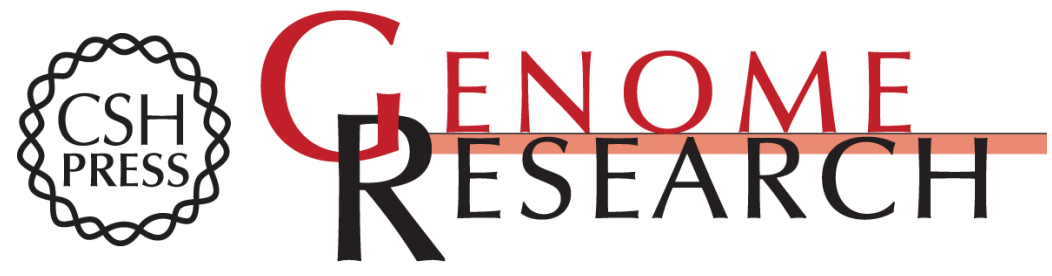

\section{A genome-wide RNA interference screen identifies new regulators of androgen receptor function in prostate cancer cells}

Keren Imberg-Kazdan, Susan Ha, Alex Greenfield, et al.

Genome Res. 2013 23: 581-591 originally published online February 12, 2013

Access the most recent version at doi:10.1101/gr.144774.112

Supplemental Material

References

Creative

Commons

License

Email Alerting Service
http://genome.cshlp.org/content/suppl/2013/02/14/gr.144774.112.DC1

This article cites 65 articles, 15 of which can be accessed free at: http://genome.cshlp.org/content/23/4/581.full.html\#ref-list-1

This article is distributed exclusively by Cold Spring Harbor Laboratory Press for the first six months after the full-issue publication date (see

$\mathrm{http}: / / g$ enome.cshlp.org/site/misc/terms.xhtml). After six months, it is available under a Creative Commons License (Attribution-NonCommercial 3.0 Unported License), as described at http://creativecommons.org/licenses/by-nc/3.0/.

Receive free email alerts when new articles cite this article - sign up in the box at the top right corner of the article or click here.

\section{Affordable, Accurate Sequencing.}

To subscribe to Genome Research go to:

https://genome.cshlp.org/subscriptions 